\title{
Diacronie
}

Studi di Storia Contemporanea

$\mathrm{N}^{\circ} 24,4 \mid 2015$

Le dittature militari: fisionomia ed eredità politica

\section{Dictadura militar y represión a la clase trabajadora}

La Armada Argentina, marco doctrinario y operaciones represivas en perspectiva regional para los casos de Ensenada y Bahía Blanca

\section{Ivonne Barragán y Ana Belén Zapata}

\section{(2) OpenEdition}

Journals

\section{Edición electrónica}

URL: http://journals.openedition.org/diacronie/3612

DOI: 10.4000/diacronie.3612

ISSN: 2038-0925

Editor

Association culturelle Diacronie

Referencia electrónica

Ivonne Barragán y Ana Belén Zapata, « Dictadura militar y represión a la clase trabajadora », Diacronie [En línea], N²4, 4 | 2015, documento 1, Puesto en línea el 29 diciembre 2015, consultado el 19 abril 2019. URL : http://journals.openedition.org/diacronie/3612 ; DOI : 10.4000/diacronie.3612 


\section{Diacronie}

N. 24 | 4|2015 Le dittature militari: fisionomia ed eredità politica

1/

\section{Dictadura militar y represión a la clase trabajadora}

\section{La Armada Argentina, marco doctrinario y operaciones represivas en perspectiva regional para los casos de Ensenada y Bahía Blanca}

Ivonne BARRAGÁN, Ana Belén ZAPATA*

La última dictadura militar en la Argentina (1976-1983), imbuida de la Doctrina de Seguridad Nacional, desarrolló diferentes formas y tecnologías represivas contra sus ciudadanos. La represión, basada en el terror de Estado, fue organizada territorialmente por el Ejército Argentino, que tuvo a su cargo la coordinación operativa a escala nacional y la construcción de un esquema tripartito de poder. Este artículo indaga la acción de la Armada Argentina en la configuración de acciones y prácticas represivas desde una perspectiva de análisis regional y de caso. Nuestro interés radica en problematizar aquellos procesos de largo plazo instaurados por la represión de la Armada en contextos acotados, las localidades de Bahía Blanca y Ensenada, y sus proyecciones en la etapa democrática. Nos interesa pensar ¿cuáles fueron las modalidades desde las cuales la ARA ejerció su acción represiva sobre un sector civil particular como fue el de los trabajadores?

\section{Introducción}

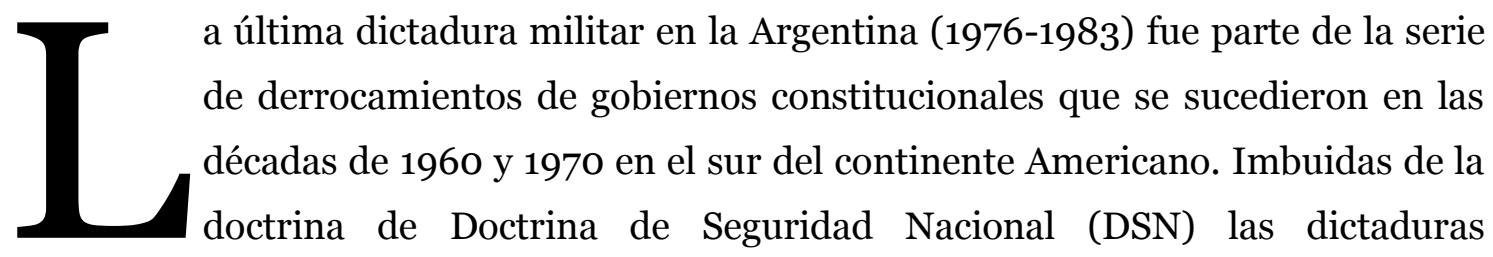


latinoamericanas desarrollaron diferentes formas y tecnologías represivas contra sus ciudadanos. En la Argentina, el terror de Estado fue organizado territorialmente por el Ejército Argentino (EA). Este ordenamiento implicó la participación del conjunto de las Fuerzas Armadas y la construcción de un esquema tripartito de poder ${ }^{1}$. La participación represiva de la Armada y la Fuerza Aérea se desarrolló con autonomía en sus jurisdicciones y ámbitos naturales. En este artículo nos preguntamos por el accionar de la Armada Argentina (ARA) en la configuración de prácticas represivas desde una perspectiva de análisis regional y de caso.

Sucesos como el bombardeo a civiles en Plaza de Mayo el 16 de junio de 1955, los fusilamientos a militantes políticos en la Base Aeronaval Almirante Zar en Trelew (1972), la Escuela Mecánica de la Armada (ESMA) como insignia del terror de Estado, requieren de interpretaciones sociohistóricas que iluminen procesos de largo plazo y a la fuerza como objeto histórico en particular². La ARA, en las figuras del contraalmirante Emilio Eduardo Massera y del Teniente de Fragata Alfredo Astiz, se constituyó en emblema de las más atroces violaciones a los derechos humanos. La deriva institucional que lanzó a la estructura operativa de la fuerza hacia el delito común instaló a su oficialidad en un descrédito público con proyección hacia la etapa democrática iniciada en $1983 \cdot{ }^{3}$

Este trabajo propone un análisis de la instrumentación de la represión desde sus marcos doctrinarios-operativos en diálogo con dos contextos regionales específicos como las zonas industriales-portuarias de Bahía Blanca y Ensenada de la provincia de Buenos Aires. Tendremos especial atención para el caso de Bahía Blanca en la actividad agroexportadora desarrollada en el Puerto de Ingeniero White, y, para Ensenada, la empresa estatal bajo gestión de la ARA Astillero Río Santiago.

1 La participación de las distintas armas en la administración del Estado alcanzó las intervenciones de medios de comunicación, sindicatos, obras sociales, organizaciones empresarias y empresas públicas. La mitad de las gobernaciones quedó en manos del Ejército y la otra mitad se repartió en partes iguales entre la Armada y la Fuerza Aérea. Cfr. CANELO, Paula, El proceso en su laberinto. La interna militar de Videla a Bignone, Buenos Aires, Prometeo, 2008, p. 79.

2 En la ESMA funcionó uno de los más grandes Centros Clandestino de Detención y Muerte (CCDyM) por donde pasaron miles de detenidos desaparecidos. Estuvo a cargo de la Fuerza de Tareas de la ARA 3.3.2. responsable de crímenes aberrantes como el sometimiento de secuestrados a trabajo esclavo, el funcionamiento de una maternidad clandestina y la apropiación de los niños nacidos, o la organización de los llamados «vuelos de la muerte» que arrojaban detenidos con vida al mar. Al respecto, véase CALVEIRO, Pilar, Poder y desaparición, Buenos Aires, Colihue, 2001.

3 URIARTE, Claudio, Almirante cero. Biografía no autorizada de Emilio Eduardo Massera, Buenos Aires, Planeta, 2011. 


\section{El Plan de Capacidades de la Armada Argentina (PLACINTARA) de 1975. Marco doctrinario para la acción represiva de la fuerza}

Extendidos acuerdos en el campo de la historia reciente señalan el año 1975 como un momento clave en la configuración del proceso represivo desarrollado luego por la dictadura militar. 4 Estudios recientes plantean la necesidad de expandir la búsqueda de los inicios de la estructura represiva del Estado hacia atrás donde se sentaron las bases de la DSN que sustituyó la preeminencia de la defensa de las fronteras nacionales por un ideario que otorgó centralidad a la figura del "enemigo interno"5.

En septiembre de 1974 fue sancionada la Ley ${ }^{\circ} 20.840$ de «Seguridad Nacional y actividades subversivas». En noviembre se declaró el Estado de Sitio, a fin de suspender las garantías constitucionales, este estado de excepción se mantuvo desde noviembre de 1974 hasta 1983. En este marco se creó el Consejo de Seguridad Interna (CSI) presidido por la presidenta María Estela Martínez de Perón y compuesto por ministros nacionales y los comandantes de las Fuerzas Armadas, y se promulgaron los Decretos Secretos $\mathrm{N}^{\circ}$ 2.770, 2.771 y 2.772 que preveían la planificación y dirección de los esfuerzos y recursos a nivel nacional para la acción contra la subversión. El 2.771 colocó bajo control operacional del EA el conjunto de fuerzas policiales y de seguridad mediante la suscripción de convenios con las provincias. Así, el Ejército organizó la totalidad del territorio nacional en cinco zonas con sus correspondientes subzonas, áreas y subáreas.

La Directiva $\mathrm{N}^{\circ} 1$ del CSI, dictada el 15 de octubre de 1975, dispuso que el accionar de todas las fuerzas debía ser conjunto ${ }^{6}$. La responsabilidad primaria de la «contienda contra la subversión» correspondió al EA e incluyó la conducción de la inteligencia para la «comunidad informativa» y el control operacional del territorio y de las diferentes

4 ÁGUILA, Gabriela, La represión en la historia reciente argentina: fases, dispositivos y dinámicas regionales, in ÁGUILA, Gabriela, ALONSO, Luciano (Coords.), Procesos represivos y actitudes sociales. Entre la España franquista y las dictaduras del Cono Sur, Buenos Aires, Prometeo Libros, 2013, pp. 97-122.

5 RANALLETTI, Mario, «Una aproximación a los fundamentos del terrorismo de Estado en la Argentina: la recepción de la noción de "guerra revolucionaria" en el ámbito castrense local (1954-1962)", in Anuario del centro de Estudios Históricos "Prof. Carlos Segreti", 11, 2011, pp. 261-278; PONTORIERO, Esteban, «Pensamiento militar y legislación de defensa en la Argentina: la caracterización de la amenaza a la seguridad interna. ¿Continuidad o ruptura? (1963-1970)», in Contemporánea, 3, 3/2012, pp. 149-166.

${ }^{6}$ La Directiva $\mathrm{N}^{\circ} 1 / 75$ se complementó posteriormente con la Directiva $\mathrm{N}^{\circ} 404 / 75$ «Lucha contra la subversión» del Comandante General del Ejército, destinada a poner en ejecución inmediata las medidas para la lucha contra la subversión. TENTONI, Eduardo, Auto de procesamiento de varios oficiales navales en la causa por crímenes contra la humanidad de la Armada Argentina, Bahía Blanca, Equipo Nikzor, 19 de septiembre de 2011, URL: < http://www.derechos.org/nizkor/arg/doc/botto2.html > [consultado el 28 de octubre de 2015]. 
fuerzas desplegadas en él7. La normativa estableció en el inciso 7 "Misiones particulares", en el punto $b$ describió las funciones de la ARA: «Operar ofensivamente a partir de la recepción de la presente Directiva, contra la subversión en el ámbito de su jurisdicción y fuera de ella en apoyo de las otras FFAA, para detectar y aniquilar organizaciones subversivas a fin de preservar el orden y la seguridad de los bienes, de las personas y del Estado» ${ }^{8}$.

A partir de estos elementos nos preguntamos ¿cuáles fueron las modalidades del ejercicio represivo de la ARA sobre un sector civil particular como fueron los trabajadores? Y ¿de qué maneras se ordenó su operatoria represiva?

El PLACINTARA, a partir de la Directiva $\mathrm{N}^{\circ} 1 / 1975$, fue una herramienta para organizar el funcionamiento represivo9. Remplazó al PLANCINTARA/1972 que debió «ser incinerado en sus respectivos destinos»y, por razones de seguridad, se previó la distribución del «mínimo imprescindible de ejemplares» ${ }^{10}$. Fueron autenticadas y distribuidas un total de 20 copias a toda la estructura de la ARA y al Ejército (Comando Cuerpo Ejército $\mathrm{V}^{\mathrm{o}}$, Comando Cuerpo Ejército ${ }^{\mathrm{o}}$ y el Comando de Instituto Militares) ${ }^{11}$. En el documento la ARA desarrolló un diagnóstico coyuntural de la etapa democrática en ciernes:

nuestro país fue convertido en activo campo de acción de la subversión marxista por la ineficiencia del gobierno, su deshonestidad administrativa, la indisciplina laboral y el envilecimiento de la economía. Las marchas y contramarchas realizadas en todos los órdenes del quehacer nacional [...] sirvieron para iniciar un acelerado proceso de desintegración de la Nación ${ }^{12}$.

La jurisdicción de la ARA comprendió: el mar, los ríos navegables, sus riberas, zonas portuarias y la zona territorial circundante a las bases y establecimientos en tierra. El esquema organizativo de la fuerza, no se basó -como en el caso del EA- en una

\footnotetext{
7 Directiva del Consejo de Defensa $N^{o} 1 / 75$ (Lucha contra la subversión), Buenos Aires, octubre de 1975, URL: < http://www.desaparecidos.org/nuncamas/web/document/militar/175.htm > [consultado el 3 de noviembre de 2015].

8 Ibídem.

9 PLACINTARA C.O.N $N^{\circ} 1$ " $S " / 75$, contribuyente a la Directiva Antisubversiva $\mathrm{N}^{\circ} 1 / 75$ Secreto, Copia $\mathrm{N}^{\circ}$ ooo, Comando General de la Armada, Comandante de Operaciones Navales, Puerto Belgrano, o8.00 21, de noviembre de 1975, $\mathrm{N}^{\circ}$ de Ref: SSH-57. El documento se compone por un cuerpo central de 20 fojas y 8 anexos: A- Inteligencia, B- Concepto de la Operación, C- Concepto de cada acción, D- Jurisdicciones y acuerdos, E- Asuntos Jurídicos, F- Personal, G- Logística, y, H- Comunicaciones. En adelante las citas referentes a este documento se desarrollarán como PLANCINTARA, fecha y número de foja.

10 PLANCINTARA, 21 de Noviembre de 1975, Foja 16 y Foja 18.

${ }^{11}$ PLANCINTARA, 21 de Noviembre de 1975, Foja 20.

12 PLANCINTARA, 21 de Noviembre de 1975, Foja 6.
} 
división del territorio bajo su jurisdicción en Zonas, Subzonas o Áreas de defensa, sino en aquellas regiones circundantes a su propia infraestructura y «al agua» como su elemento natural de acción ${ }^{13}$. El PLACINTARA estableció que los comandos, organismos y dependencias de dicha fuerza constituirían, a los fines de combatir la subversión, una «sola Zona de Defensa».

En este artículo nos centraremos en dos áreas de interés para la fuerza ${ }^{14}$ : las localidades de Berisso y Ensenada como «Áreas de Interés y Agencias de Colección», y las áreas de Punta Alta y Bahía Blanca dentro del área de incumbencia de la Base Naval Puerto Belgrano, uno de los más importantes establecimientos navales, ubicado al sur de la provincia de Buenos Aires, bajo control operacional del Comando de Operaciones Navales - que era la principal autoridad operativa de la ARA - y el Comando Naval ${ }^{15}$. Para las mismas, el PLANCITARA contemplaba la conveniencia de garantizar una amplia libertad de acción e iniciativa regionali6. En la práctica esta lógica implicó enorme discrecionalidad en el funcionamiento de los dispositivos represivos.

La ARA organizó un total de 11 Fuerzas de Tareas. Las Fuerzas de Tareas (FT) con asiento en la zona de Punta Alta-Bahía Blanca eran: FT 1 "Flota de Mar”, perteneciente a la Base Naval Puerto Belgrano (BNPB) y la FT 2 "Fuerza de apoyo Anfibio" que correspondía a las dependencias en Bahía Blanca y Punta Alta de la Prefectura Naval Argentina, así como la Prefectura Zona Atlántico Norte y la Prefectura Bahía Blanca. Por otra parte, la FT9 "Reserva Terrestre" comprendía el Batallón Comando (BICO) de la Brigada de Infantería de Marina No 1 (BRIM1) y en la FT1o "Reserva Aeronaval"

13 PLANCINTARA, 21 de Noviembre de 1975, Foja 8.

14 Estableció 11 áreas de interés principal: Punta Alta y Bahía Blanca; Capital Federal y Gran Buenos Aires; Zárate; Puerto Belgrano; Ensenada y Berisso; Mar del Plata; Trelew, Rawson y Puerto Madrin; Ushuaia, Río Gallegos y Río Grande; Verónica; Puntos del Litoral y vial. PLANCINTARA, o9 de Abril de 1980, Fojas 1 y 2 del Apéndice al Anexo A.

15 Sequicentenario de Bahía Blanca, 150 años de Historia 1828-1878, Bahía Blanca, Ed. Crismar, 1978.

${ }^{16}$ La descripción de misiones y funciones del PLANCINTARA para la escala regional fueron desarrolladas en el anexo B. Punto 1.1: «La complejidad de la subversión y las características del enemigo imponen la necesidad de emplear los medios de la ARMADA disponibles en su jurisdicción con la más amplia libertad de acción e iniciativa regional, para intervenir en todas aquellas situaciones en que puedan existir contracciones subversivas». Cfr. Plan de Capacidades (PLANCINTARA) Secreto, Copia No oooo, Comando General de la Armada, 21 de Noviembre de 1975, Foja 1 de Anexo B. Ya la historiadora Gabriela Águila señalaba la importancia de la dimensión regional para acercarnos a una mayor complejidad en la recuperación histórica de los procesos represivos considerando «no sólo las relaciones entre el diseño del plan desde arriba» desde el aparato estatal/nacional y su implementación a escala local/regional sino también la disponibilidad de recursos y los variables grados de autonomía en el accionar de las fuerzas intervinientes. ÁGUILA, Gabriela, «La represión en la historia reciente argentina: fases, dispositivos y dinámicas regionales» in ÁGUILA, Gabriela, ALONSO, Luciano (Coords.), Procesos represivos y actitudes sociales. Entre la España franquista y las dictaduras del Cono Sur, cit., p. 99. 
comprendía a los grupos de tareas por la Base Aeronaval Comandante Espora y el Taller Aeronaval Central17.

Para Ensenada, la FT5 "Agrupación Río Santiago" incluyó en su zona de incumbencia: la Escuela Naval Militar (ubicada frente a al ARS, cruzando el Río Santiago), el Liceo Naval Almirante Brown, el Hospital Naval Río Santiago, el Batallón de Infantería de Marina $\mathrm{N}^{\circ} 3$ (BIM3), Prefectura La Plata, Centro de Incorporación y Formación de Conscriptos de Infantería de Marina; dependencias con asiento en La Plata, Berisso y Ensenada ${ }^{18}$.

\section{Las regiones y sus potencialidades productivas}

Las localidades de Berisso y Ensenada en la Provincia de Buenos Aires fueron zonas de industrialización y asiento de población proletaria temprana. El crecimiento poblacional resultó de las sucesivas etapas de radicación de industrias en la región. Primero, de grandes frigoríficos, prósperos en la década de 1940 en contexto internacional de Segunda Guerra Mundial ${ }^{19}$. En el año 1922 se estableció una Destilería de la empresa estatal Yacimientos Petrolíferos Fiscales (YPF). Esta planta diversificó la actividad económica de la región, alcanzó a producir el 30\% del consumo nacional de combustibles y empleó aproximadamente a 7.000 operarios. ${ }^{20}$ En los '60 se radicaron empresas del sector petroquímico en las tierras bajas de Ensenada. La concentración industrial en la región implicó la convivencia de un conjunto de pequeñas y medianas empresas - muchas de ellas dedicadas a la producción de autopartes - junto a establecimientos de actividades dinámicas - siderúrgica, metalúrgica y química - como fueron las empresas IPAKO, Propulsora Siderúrgica y la Petroquímica General Mosconi $^{21}$.

El proceso de industrialización por sustitución de importaciones (ISI) iniciado en la década de 1930 y hasta los años 70 reservó lugares de privilegio para las Fuerzas Armadas (FFAA) en la estructura de gestión del Estado y en la construcción de un

${ }_{17}$ PLANCINTARA, parte: “Organización”, Pto. a), pp. 2-20.

18 PLANCINTARA, 21 de Noviembre de 1975, Foja 4.

${ }^{19}$ La mayor parte de la industria de la carne se instaló en la localidad de Berisso, en 1904 comenzó a funcionar el frigorífico de capitales sudafricanos Cold Storage \& Co. que en el año 1911 fue adquirido por la empresa norteamericana Swift, en el año 1915 se instaló el frigorífico, Amour.

20 ROMÁ, Pablo, «Acumulación de capital y conflictividad social en La Plata, Berisso y Ensenada, 1966-1969", in CASTILLO, Christian, RAIMUNDO, Marcelo (Coords.), El 69 platense. Luchas obreras, conflictos estudiantiles y militancia de izquierda en La Plata, Berisso y Ensenada durante la Revolución Argentina, Buenos Aires, Estudios Sociológicos Editora, 2012, p. 170.

${ }^{21}$ Ibidem, p. 169. 
complejo industrial militar diversificado. El mayor número de empresas de este complejo industrial-militar estuvo bajo la órbita de la Dirección General de Fabricaciones Militares (DGFM) cuya administración correspondió al EA ${ }^{22}$. En la región de Berisso y Ensenada se emplazaron dos empresas bajo gestión de las FFAA, la Fábrica Militar de Acido Sulfúrico de la DGFM y el Astillero Río Santiago de la Marina de Guerra. Concentraremos nuestro interés en el desarrollo de la acción represiva de la ARA sobre el colectivo de trabajadores de este último ${ }^{23}$.

Hacia finales de la década de 1960 el ARS empleaba 5.000 trabajadores en planta permanente y aproximadamente otros 3.000 desempeñaban tareas productivas a través de empresas subcontratistas ${ }^{24}$. Había alcanzado una capacidad productiva potencial de 50.000 toneladas de porte bruto anuales en buques mercantes y su equivalente en buques de guerra y era el primer astillero integrado de América del Sur. Desde la década de 1960 se diversificó hacia la manufactura de bienes de capital e insumos para industrias dinámicas 25 .

Esto marcó la singularidad del ARS: una empresa de gestión de la ARA, producción naval militar - estratégica - para la defensa y diversificada. En el período inmediato anterior a la dictadura se agudizó el proceso de acción colectiva de sus trabajadores a partir de la organización sindical de base y el cuestionamiento del régimen de autoridad militar que suscitó conflictos por salario, cuestionamientos al orden industrial y a las condiciones generales de trabajo. Estos elementos constituyeron los fundamentos de la instrumentación de una acción represiva con fuerte proyección regional ${ }^{26}$. En el caso del ARS observamos que, ante el conflicto obrero, la implementación de la represión de

${ }^{22}$ La Dirección General de Fabricaciones Militares (DGFM) fue fundada el 26 de septiembre de 1941, mediante la Ley N ${ }^{\circ}$ 12.709. Dirección General de Fabricaciones Militares, Buenos Aires, URL: < http://www.fab-militares.gov.ar/quienes-somos/ > [consultado el 10 de noviembre de 2015].

${ }^{23}$ El ARS tuvo sus orígenes en los talleres de la Base Naval de Río Santiago en la década de 1930. En el año 1946 se iniciaron las obras en tierra firme, sobre la margen sur del río. En 1953 se constituyó la empresa Astilleros y Fábricas Navales del Estado (AFNE) que comprendía al Astillero Río Santiago y la Fábrica Militar de Pólvoras y Explosivos de Azul (FANAZUL) situada en esa localidad de la Provincia de Buenos Aires. Su directorio se conformó principalmente por personal de la Armada en estado de retiro de la actividad.

24 AFNE fue la primera empresa estatal en constituir una Sociedad Anónima, el 8 de octubre de 1969, bajo la Ley 18.394. El 96\% de su paquete accionario quedó en poder del Ministerio de Defensa Nacional, que delegó su gestión a la ARA, y el restante 4\% paso a la DGFM.

${ }_{25}$ CAFFASO, María Elena, Astillero Río Santiago, Provincia de Buenos Aires, AFNE, 2004.

${ }^{26}$ Las medidas de disciplinamiento y represión de la ARA en la empresa datan de 1975: la implementación reiterada del lock out y la militarización - desde agosto de 1975 la empresa instaló un infante de Marina armada cada tres operarios en algunos de los talleres - fueron algunas de ellas. Ver BARRAGÁN, Ivonne, "Para el bien de la Nación”. Gestión militar de empresas estatales, prácticas de integración y represión de la fuerza de trabajo desde la perspectiva de caso. El Astillero Río Santiago 1973-1976», in Avances del Cesor, 10, 2013, pp. $53-72$. 
la ARA alcanzó dimensiones brutales y se correspondió con una temporalidad atenta a las necesidades de la dirección de la empresa y de la fuerza por fuera de la temporalidad represiva del plan "desde arriba".

En contraste con el caso anterior la proyección productiva y económica de Bahía Blanca en las décadas de 1960 y 1970 fue deudora de un proyecto de «promoción industrial» que perseguía convertirla en un «polo de desarrollo»27. En agosto de 1968, se declaró a Bahía Blanca como Polo de crecimiento provincial número uno, a fin de descentralizar la actividad económica y generar obras y planes que facilitaran el desarrollo.

La diversidad en los establecimientos industriales en la zona comprendía los vinculados a la metalurgia, la construcción y reparación de maquinaria y de material de transporte. En la región también se destacaba el desarrollo de los frigoríficos de carne y fruta; y en lo textil, los establecimientos de procesamiento de lana ${ }^{28}$. Algunas cuestiones que hacían a la potencialidad de Bahía Blanca como "polo de desarrollo» tenían que ver específicamente con su salida portuaria, que crecía diariamente en su actividad exportadora, en comparación con otras zonas portuarias a nivel nacional. El Puerto de Ingeniero White ${ }^{29}$, en estos años, se dedicaba específicamente a tres tipos de tráficos: combustibles, cereales y de carga en general -especialmente de frutas provenientes del valle de Río Negro y de Neuquén-. Bahía Blanca se constituyó en el puerto de embarque más grande sobre la costa atlántica, al sur de Buenos Aires y los sectores empresariales locales construyeron un "plan de desarrollo" para Bahía Blanca que la posicionaría como puerta de entrada hacia el sur patagónico.

Este proyecto, si bien tuvo su origen en gobiernos de facto, no se interrumpió durante el período constitucional (1973-1976). Hacia fines de la década de 1960 comenzaron las tratativas y proyectos para construir la Petroquímica de Bahía Blanca cuya construcción comenzó en 1973 en cercanías de la zona portuaria y sus primeras instalaciones fueron inauguradas por Jorge Rafael Videla en 1977. La Base Naval Puerto Belgrano fue creada hacia finales del siglo XIX, para los años '7o funcionaba como uno de los enclaves de ARA más relevantes del país. Ubicada en las cercanías de una ciudad donde confluían diversas fuerzas militares, en razón de necesidades

${ }_{27}$ Bahía Blanca sería incluida entre 8 polos ubicados en distintas zonas del país: Tucumán, Corrientes-Resistencia, Posadas, Neuquén-Río Negro, Puerto Madryn, Comodoro Rivadavia y Río Gallegos.

${ }_{28}$ Discurso del Ministro de Economía de la Provincia de Buenos Aires Dr. José María Dagnino Pastore pronunciado en el acto realizado el 31 de agosto de de 1968, publicado en Bahía Blanca Polo de desarrollo, Buenos Aires-La Plata, Ministerio de Economía de la Provincia de Buenos Aires, 1968.

29 Este puerto ocupaba el tercer lugar a nivel nacional después de los de Buenos Aires y Rosario. 
estratégicas de finales del siglo XIX y principio del XX, tendientes a consolidar las fronteras del Estado incluso y ganar el territorio a las poblaciones originarias de la zona.

Las distintas fuerzas militares alcanzaron una inusitada preponderancia en términos de impacto en la sociedad bahiense, la amplificación de la "voz militar", fue viabilizada por el diario local La Nueva Provincia, propiedad de la familia Massot ${ }^{30}$. Este medio fue desarrollando, hacia mitad del siglo $\mathrm{XX}$, una línea editorial conservadora y marcadamente afín al discurso militar en general y a la ARA en particular, con la cual estrechó vínculos en los años cincuenta, con posterioridad al derrocamiento del gobierno de Juan Domingo Perón, que había clausurado diario. Durante el gobierno militar de la autodenominada "Revolución Libertadora" (19551958) la ARA le ‘devolvió’ el diario a la familia Massot.

En LNP, Luis María Mendía - Comandante de Operaciones Navales - advertía, hacia fines de 1975, sobre el inicio de un período «en el que el adiestramiento y las operaciones de lucha contra la subversión pasarán a tener absoluta prioridad». Mendía anunciaba la coordinación de acción con otras fuerzas militares:

las fuerzas navales, aeronavales y de infantería de marina dedicarán prioritariamente su esfuerzo por alistarse y actuar en todas las oportunidades que se haga necesario, ya sea dentro de la jurisdicción asignada a la Armada o ya sea en apoyo de nuestro glorioso, heroico y querido Ejército Argentino, en todo lugar, época o circunstancia que dicha fuerza hermana lo requiera ${ }^{31}$.

\section{La represión de ARA sobre trabajadores en Ensenada, el Astillero Río Santiago}

El secuestro de trabajadores y representantes sindicales de base en predios fabriles fue una práctica extendida en el país durante la última dictadura militar; aunque en

\footnotetext{
${ }^{30}$ Este diario, fundado en 1898 por Enrique Julio resultó bautizado como "La Nueva Provincia" expresando una idea «...que defendía la creación de un estado federal que abarcara los partidos del sur de la provincia de Buenos Aires y las gobernaciones que se extendían a lo largo de los ríos Negro y Colorado y que tuviese a la ciudad de Bahía Blanca como capital. El matutino esgrimía como argumento principal la inadecuada organización institucional que mantenía a estas regiones en una situación de letargo crónico». Cfr. LLULL Laura, Prensa y política en Bahía Blanca. La Nueva Provincia en las presidencias radicales 1916-1930, Bahía Blanca, EdiUNS, 2005, p. 45.

${ }^{31}$ Diario La Nueva Provincia, 29 de noviembre de 1975.
} 
muchas regiones industriales, la represión ilegal de las bandas para-estatales había iniciado al menos un año antes ${ }^{32}$.

En referencia al Astillero Río Santiago sostenemos que la incumbencia institucional de la ARA en la empresa profundizó la voluntad represiva de la FT5 sobre los trabajadores del astillero y se ancló en percepciones de larga data sobre la pertenencia de la empresa a la fuerza. La sistematización de los secuestros y asesinatos de delegados combativos del astillero y de otras fábricas de la región obturaron las condiciones de posibilidad de continuidad de instancias de organización fabril a nivel regional como fue la Coordinadora de Comisiones Internas y delegados en luchas durante $1975^{33}$.

Consideramos que la represión de la ARA sobre los trabajadores, si bien se encontró imbuida del programa general de las fuerzas armadas y de la DSN, tuvo como interés particular, no solo asegurar la implantación de una racionalidad económica en la empresa, sino también ponderar la política de reconstitución de la hegemonía en sus dimensiones espaciales y de gestión de los cuerpos en el astillero como su «ámbito natural»34. En este caso la acción represiva tuvo por base intereses particulares, de rasgos revanchistas, de un sector de la oficialidad de la ARA en torno al disciplinamiento de un colectivo obrero que se desempeñaba en un ámbito considerado propio por los marinos. A lo largo de 1976 fueron detenidos y permanecen desaparecidos 16 trabajadores del ARS, en 1977 fueron secuestrados y permanecen desaparecidos 13 trabajadores, en el año 1978, registramos 3 desapariciones más. Sobre

${ }^{2}$ Durante la segunda mitad de 1975 y en el verano de 1976 fueron asesinados cinco trabajadores del ARS. El 13 de Noviembre de 1975 fue asesinado Mario Noriega, hijo de un Capitán de Navío de la ARA; el 19 de febrero de 1976 fue asesinado el técnico Alcides Méndez Paz, el 19 de marzo de 1976 fueron secuestrados tres trabajadores, Fortunato Agustín Andreucci, sub-delegado de la sección de fundición, Jorge Pedro Gutzo delegado, técnico electricista y José Luis Lucero. Cfr. Informe Nunca Más, CONADEP, t. II, Buenos Aires, EUDEBA, 2006, p. 1075, p. 1064, p. 981, p. 1037. Los testimonios coinciden en que Andreucci reconoció a quien comandaba el grupo de tareas como el Capitán Bigliardi, jefe de seguridad del ARS. Cfr. RAMíREZ, Ana Julia, MERBILHAÁ, Margarita (eds.), Memorias del BIM. Biografías. Las víctimas de la Fuerza de Tareas 5 en La Plata, Berisso y Ensenada, La Plata, Universidad Nacional de Mar del Plata, 2015, pp. 46-49, p. 57.

$33 \mathrm{El} 13$ de enero de 1976 fueron secuestrados los miembros de la comisión interna de la empresa Propulsora Siderúrgica y dirigentes de la Coordinadora regional Salvador Delaturi y Juan Carlos Scaffide. Sus cuerpos aparecieron dinamitados debajo de un puente un día después. Una investigación periodística sobre la banda para-estatal Concentración Nacional Universitaria (CNU) sostiene que la Armada solicitó a la CNU dichos asesinatos. CECCHINI, Daniel y ELIZALDE LEAL, Alberto, La CNU. El terrorismo de Estado antes del golpe, Buenos Aires, Una investigación de Miradas al Sur, 2013, pp. 23-24. Sobre la experiencia de la coordinadora regional ver, WERNER, Ruth, AGUIRRE, Facundo, Insurgencia obrera en la Argentina, 19691976. Clasismo, coordinadoras interfabriles y estrategias de la izquierda, Buenos Aires, IPS, 2007.

34 BARRAGÁN, Ivonne, ¿Quién construye la Nación? Obreros y militares en el Astillero Río Santiago. Procesos de trabajo, violencia y represión (1969-1979), Tesis Doctoral, Universidad de Buenos Aires, Buenos Aires, 2015. 
los secuestros y desapariciones de otros 10 trabajadores no hemos podido recabar datos precisos. Estas cifras ubican al ARS como la empresa con más delegados sindicales, militantes políticos y trabajadores desaparecidos (42 trabajadores) y asesinados del país (10 trabajadores) 35.

El proceso represivo de magnitudes brutales se desplegó por toda la fábrica y se extendió a empresas radicadas en la región, especialmente representantes sindicales de los frigoríficos en la localidad de Berisso. En este marco, la ARA convirtió al astillero en parte de su unidad operativa para la región sin dejar de lado la actividad productiva. El asesinato, en un atentado, del Jefe de Seguridad del ARS ${ }^{36}$ generó una sucesión de acciones represivas hacia junio de 1976; de las que resultaron víctimas cinco trabajadores, quienes permanecieron detenidos en el $\mathrm{BIM}_{3}{ }^{37}$. Los cuerpos fueron encontrados sin vida con fuertes signos de torturas ${ }^{38}$. Muchos de los trabajadores secuestrados -tanto del astillero como de otras empresas de la zona- fueron trasladados a la Escuela Naval que funcionaba frente a la planta y compartía con el ARS el muelle desde sus instalaciones. La empresa, al incorporarse de pleno al funcionamiento del esquema represivo de la FT5, prestó vehículos e infraestructura, que fueron utilizados en el secuestro y traslado de las víctimas, habilitó el uso de un espacio y cedió un área a la Sección de Tracción Terrestre de la $\mathrm{FT} 55^{39}$.

35 Recientemente el Tribunal Oral en lo Criminal Federal de la Plata Nro. 1 juzg., en el marco de la causa: Causa $\mathrm{N}^{\circ}$ 17/2012/TO1, caratulada «VAÑEK, Antonio y otros s/ Privación ilegal de la libertad» a 5 integrantes de la Armada y 3 de Prefectura por los crímenes cometidos contra trabajadores en las localidades de Berisso y Ensenada por la FT5 de la ARA. La Tesis Doctoral, BARRAGÁN Ivonne, ¿Quién construye la Nación? Obreros y militares en el Astillero Río Santiago. Procesos de trabajo, violencia y represión (1969-1979) fue insumo tanto en los alegatos acusatorios formulados por la Unidad Fiscal Federal creada por Resolución de la Procuración General de la Nación $\mathrm{N}^{\circ} 46 / \mathrm{O} 2$, para intervenir en las causas por violaciones a los derechos humanos cometidas durante la etapa de terrorismo de Estado como para la construcción de los fundamentos históricos de la sentencia. La sentencia del TOF N1 previó, por primera vez, un reconocimiento moral y económico para los trabajadores del ARS en tanto los daños infligidos por la ARA en tanto la misma se encontraba a cargo de la gestión de la empresa y ordenó la investigación de la responsabilidad empresarial, civil y militar y las complicidades de la dirección sindical.

${ }^{36}$ El Día, 14 de junio de 1976.

37 Los trabajadores secuestrados fueron seis. Solo Juan Alberto Beker, operario de la sección cobrería, sobrevivió a la masacre. Según su testimonio el operativo fue planificado en represalia por el asesinato del Capitán Bigliardi. en: Presentación ante la Cámara Federal de La Plata, Comisión por la Verdad hacia la Justicia de la Central de Trabajadores Argentinos, marzo de 2000, pp. 17-18. Todos los testimonios disponibles indican la acción de la ARA en relación al llamado " $5 \times 1$ " por el cual por cada hombre caído en un bando se asesinarían cinco del contrario. ${ }^{38}$ Los trabajadores asesinados fueron Leonardo Diego Arias, operario de refrigeración de los barcos, Juan Carlos Arriola; Héctor Rolando García Dulce, supervisor; José Edgardo Cardinale, técnico y Roberto Luciano Sanders, medio oficial calderero y dirigente sindical. Informe Nunca Más, CONADEP, t. I, Buenos Aires, EUDEBA, 2006, p. 374, p. 179, p. 69; Informe Nunca Más, CONADEP, t. II, Buenos Aires, EUDEBA, 2006, p. 826.

39 A mediados de 2015 tuvo inicio el juicio por crímenes cometidos durante la última dictadura militar por la Fuerza de Tareas 5 de la Armada. Cfr. La Plata: marinos y prefectos serán 
En el predio de la Escuela Naval funcionó, durante un breve tiempo, un centro clandestino de detención dentro del cual se realizaron mediante tortura, los primeros interrogatorios. El PLACINTARA establecía la doble dependencia de las unidades navales, una operativa y otra administrativa, lo que implicó que el Director de la Escuela Naval fuera - al mismo tiempo - Comandante de la Fuerza de Tareas $\mathrm{N}^{\circ} 5$ a cargo de las tareas operativas de «lucha contra la subversión» en su jurisdicción ${ }^{40}$. Durante los meses posteriores al 24 de marzo de 1976, los detenidos - trabajadores del ARS y la región - fueron llevados a dependencias de la Armada: la Escuela Naval Militar, el Batallón de Infantería de Marina $\mathrm{N}^{\circ} 3$ y sub prefectura de Ensenada. Posteriormente, muchos de los trabajadores secuestrados fueron destinados a diferentes centros clandestinos dependientes de fuerzas del llamado Circuito Camps ${ }^{41}$.

\section{Accionar represivo de la ARA sobre trabajadores en Bahía Blanca y la región}

La estructuración del accionar represivo a partir del 24 de marzo de 1976 en la zona de Bahía Blanca y Punta Alta excedió la operatoria de la ARA. Dentro del esquema que dividió al territorio nacional en 5 zonas, Bahía Blanca comenzaba la jurisdicción del comando de la zona $5^{\circ}$ a cargo del V Cuerpo de Ejército, ésta abarcaba el sur de la provincia de Buenos Aires, y las provincias de Río Negro, Chubut, Santa Cruz y el territorio de Tierra del Fuego.

Entre los centros clandestinos de detención (CCD) establecidos en la ciudad, el mayor fue el complejo conocido como "La Escuelita", una casa antigua ubicada en cercanías a los terrenos del V Cuerpo del EA por donde pasaron muchas de las víctimas del terrorismo de Estado en la zona, quienes padecieron allí las peores condiciones de

juzgados por los crímenes de la Fuerza de Tareas 5, Nuevo Código Procesal Penal de la Nación, 10 de julio de 2015, URL: < https://www.fiscales.gob.ar/lesa-humanidad/la-plata-marinos-yprefectos-seran-juzgados-por-los-crimenes-la-fuerza-de-tareas-5/ $>$ [consultado el 12 de octubre de 2015]. En Bahía Blanca, el 8 de julio de 2014 comenzó el juicio por delitos de Lesa Humanidad cometidos por la ARA en la zona. Cfr. Bahía Blanca: comenzó el juicio oral contra 24 marinos, prefectos, militares y penitenciarios, Nuevo Código Procesal Penal de la Nación, 8 de julio de 2015, URL: < https://www.fiscales.gob.ar/lesa-humanidad/bahia-blanca-comenzoel-juicio-oral-contra-24-marinos-prefectos-militares-y-penitenciarios/ > [consultado el 12 de octubre de 2015].

${ }^{40}$ La Plata: marinos y prefectos serán juzgados por los crímenes de la Fuerza de Tareas 5, Nuevo Código Procesal Penal de la Nación, 10 de julio de 2015, URL: < https://www.fiscales.gob.ar/lesa-humanidad/la-plata-marinos-y-prefectos-seran-juzgados-porlos-crimenes-la-fuerza-de-tareas-5/ > [consultado el 12 de octubre de 2015].

${ }^{41} \mathrm{El}$ "Circuito Camps" recibe su nombre por el entonces jefe de la Policía de la Provincia de Buenos Aires Coronel Ramón Camps. En este circuito funcionaron, con diferentes temporalidades, más de veinte Centros Clandestinos de Detención. 
hacinamiento, interrogatorios bajo tortura y vejámenes ${ }^{42}$. En la zona el enclave central de la ARA fue la Base Naval Puerto Belgrano, sede del Comando de Operaciones Navales que era la principal autoridad de la Armada, según el PLACINTARA. Los CCD dependientes de la ARA en la región fueron el Buque "ARA 9 de julio", que se encontraba amarrado en una de las dársenas de la Base Naval de Puerto Belgrano y "Baterías" que se encontraba bajo jurisdicción de la Base de Infantería de Marina.

La circulación de las víctimas por estos espacios de confinamiento clandestino fue continua a partir de la acción coordinada de las distintas fuerzas, a lo que también debemos sumar el paso transitorio por dependencias de la policía (Federal o la de la Provincia de Buenos Aires) y las dependencias de la Unidad Penitenciaria No 4 en Villa Floresta. A la cárcel fueron trasladadas las víctimas "blanqueadas" o puestas a disposición del Poder Ejecutivo Nacional luego de pasar por algún CCD. En el espacio cercano al área de puertos, esto es, en Ingeniero White, los operativos estuvieron signados por la imponente circulación de camiones militares o provenientes de la Base Naval que afectaron la cotidianeidad de los trabajadores en ese espacio. Muchos trabajadores fueron secuestrados en sus casas, frecuentemente por la noche, en el espacio laboral, o en el trayecto hacia el trabajo.

Si pensamos cómo afectó la represión a los trabajadores de la zona, no deberíamos abstraernos de un contexto local y regional en donde operó una extensa temporalidad de convivencia de los colectivos obreros con enclaves militares y fuerzas de seguridad. Esta presencia, dio lugar a cierta condensación de años de experiencias de represión, cárcel, detenciones, etc. como respuestas hacia formas de conflicto y luchas obreras ${ }^{43}$. Por estos años, la instauración de políticas de "racionalización" económica requirió del control efectivo de los lugares de trabajo y la implementación de reglamentaciones laborales que atentaron hacia distintas conquistas obreras.

Los principales sectores de trabajadores que protagonizaron conflictos, luchas, y/o resistencias al proyecto de "racionalización" y crecimiento urbano-productivo iniciado en los años '6o, tuvieron una contrapartida represiva, además, de ajustes aleccionadores de las condiciones de trabajo y la disciplina en el espacio laboral. Para muchos trabajadores y sindicalistas locales, la violencia represiva de la que fueron víctimas estuvo fundada en la "respuesta" militar a los posibles "focos conflictivos" que atentarían contra la concreción del tan ansiado "despegue productivo" de los sectores

42 Otras edificaciones que funcionaron como $\mathrm{CCD}$ fueron dependencias pertenecientes al Batallón de Comunicaciones 181.

43 ZAPATA, Ana Belén, Andamios de experiencias: Conflictividad obrera, vigilancia y represión en Argentina. Bahía Blanca, 1966-1976, Tesis de Doctoral, Universidad Nacional de La Plata - Mimeo, La Plata, 2014. 
de empresarios locales. Estos últimos, a su vez, creyeron que ese despegue se materializaría de hecho con el advenimiento de las medidas económicas aplicadas por la Junta Militar a partir de 1976, concretamente ante la puesta en funcionamiento de la Petroquímica Bahía Blanca44.

El comunicado $\mathrm{N}^{\circ} 7$ del Comando de Subzona 51 -dado a conocer públicamente un día después del golpe de Estado- convocó a presentarse a toda persona vinculada a los distintos gremios. Desde el Comando se hizo especial hincapié en la presencia de los secretarios generales, quienes debían hacerse presentes el 26 de marzo, a una reunión, a fin de tratar temas como «clausura de los sindicatos, cuidados de los bienes y obra social de los sindicatos» 45 .

Las detenciones por parte de la ARA, en términos generales, significaron un primer paso por dependencias de Prefectura, y, posteriormente, por el Buque ARA 9 de julio, aunque también hubo casos de traslado a dependencias militares de otras fuerzas ${ }^{46}$. Podemos individualizar algunos de los sectores más afectados por el accionar represivo ejercido desde la ARA, a saber: los estibadores agremiados en SUPA, los trabajadores de la Junta Nacional de Granos (JNG), los empleados de la termoeléctrica, de la empresa estatal de telecomunicaciones (ENTEL)47 y trabajadores ferroviarios - con centralidad aquellos con lugar de trabajo en el Galpón de Máquinas de Ingeniero White- .48 Para el caso de la JNG algunos de sus empleados y/o sindicalistas, resultaron

\footnotetext{
44 Libro de los 60 años de la Corporación del Comercio y de la Industria de Bahía Blanca, Bahía Blanca, Ed. Encestando, 4 de mayo 1979.

45 La Nueva Provincia, 26 de marzo de 1976.

${ }^{46}$ El testimonio del delegado de la Asociación de Trabajadores del Estado (ATE) Raúl Edgardo Carracedo-en el marco de la Causa por delitos de Lesa humanidad en la ARA- da cuenta de traslado desde el Buque hacia CCD de otras fuerzas. Véase: Requerimiento de elevación a juicio de diciembre 2012, Causa $\mathrm{N}^{\circ}$ O4/O7. Investigación de delitos de Lesa Humanidad -Causa ARA. 47 La Central Termoeléctrica de Bahía Blanca fue tomada por la ARA el 24 de marzo de 1976. Para el caso de empleados de la Empresa Nacional de Telecomunicaciones (ENTEL) de Bahía Blanca; o de gremialistas de Luz y Fuerza de Punta Alta, como fue el caso de Hugo Giorno que fue secuestrado el 24de marzo de 1976, desde un colectivo en el que viajaba a Punta Alta y llevaron a la Base Naval de Puerto Belgrano, luego estuvo en el CCD buque ARA 9 de julio, después fue al V Cuerpo de Ejército y estuvo encerrado en el gimnasio del Batallón de Comunicaciones 181. También su hermano Néstor Giorno, agremiado en Luz y fuerza fue secuestrado ese mismo día y llevado al buque ARA 9 de julio, de allí al Batallón de Comunicaciones 181. (Véase: Requerimiento de elevación a juicio de diciembre 2012, Causa $\mathrm{N}^{\circ}$ 04/07).

48 Entre los ferroviarios, cabe mencionar el caso de Héctor Ramón Duck, de la Unión Ferroviaria, secuestrado por la Prefectura Naval e interrogado en dependencias de la Prefectura de Bahía Blanca en White. Luego fue trasladado a la sede de Prefectura de Zona Atlántico Norte, y de allí fue llevado hacia el V Cuerpo de Ejército. Finalmente lo llevaron al CCD "La Escuelita" que dependía de esa fuerza y donde fue víctima de torturas. Otro caso fue el de Juan Antonio Fernández, secuestrado desde el galpón de Máquinas en Ingeniero White y luego trasladado a la Prefectura. (Véase: Requerimiento de elevación a juicio de diciembre 2012, Causa $\mathrm{N}^{\circ} 04 / 07$ ).
} 
detenidos por personal de la Prefectura 49. Otro sector que se vio fuertemente afectado por el accionar represivo de la ARA fue el de los estibadores del puerto. Fueron numerosos los trabajadores de ese ámbito y/o sindicalistas del SUPA que resultaron secuestrados por el personal de la Prefectura Naval Argentina50.

La operatoria represiva de la ARA no debe ser analizada independientemente del trabajo minucioso de los servicios de inteligencia de esta fuerza sobre las víctimas. En este sentido, el papel que jugaron los servicios de seguimiento en la estructuración de la represión fue central51. Un caso específico, que refiere a la operatoria de los servicios de inteligencia de la Prefectura Naval, fue el señalamiento de los trabajadores que resultaban "molestos" a la empresa periodística del diario La Nueva Provincia5². En dicho informe figuraban los trabajadores a "ser raleados" del medio periodístico que la ARA consideraba "fundamental" para la sociedad bahiense53. Este es tan solo uno de los casos que nos habilita a pensar concretamente la vinculación entre la vigilancia, el señalamiento y la persecución con su posterior consecuencia represiva.

Un informe de inteligencia de la Prefectura Naval fechado el 14/o6/1976 - algunos meses después de producido el golpe de Estado - detallaba por ejemplo el estado y la

49 En algunos de estos casos, observamos detenciones de sectores militantes de la derecha ortodoxa del peronismo, que habían participado entre 1974 y 1976 en organizaciones paraestatales o funcionando como grupos de choque. Cfr. ZAPATA, Ana Belén, «Violencia parapolicial en Bahía Blanca, 1974-1976. Delgados límites entre lo institucional y lo ilegal en la lucha contra la "subversión apátrida"», in Anos 9o, 35, 2012, pp. 111-140; y ZAPATA, Ana Belén, «Pensar la escalada de violencia y la violencia en escalas. Entramados de la "lucha antisubversiva” pre-dictatorial. Bahía Blanca, 1974/1976» in Avances del Cesor, 12, 2015, pp. 141-156.

${ }^{5}$ En esa situación encontramos a Orlando Apud que era delegado del SUPA fue llevado al CCD del buque ARA 9 de julio donde fue interrogado. Fue liberado luego de siete meses del secuestro. También Ramón Oscar Reynafé, Ernesto Reynafé, Anibal Marziani, Crisólogo Segundo Alfaro, Edgardo Ponce, Aman Petit, sufrieron hechos similares. Emiliano Osores que era Secretario General del SUPA, fue secuestrado por la Prefectura pero a diferencia de los otros casos, fue llevado al V Cuerpo de Ejército. Raúl Florido, estibador, fue detenido el 25/03/1976 por Prefectura, llevado al Comando V Cuerpo y después de allí al Batallón Comando 181. Observamos la circulación de las víctimas por centros de detención que no siempre fueron necesariamente dentro de la ARA. (Véase: Requerimiento de elevación a juicio de diciembre 2012, Causa $\mathrm{N}^{\circ} \mathrm{O} 4 / \mathrm{O} 7$ ).

${ }^{11}$ Nos valemos del fondo documental producido en la época por la Sección Informaciones de la Prefectura Naval Argentina Zona del Atlántico Norte (SIPNA), este acervo dependía directamente de la Armada y correspondía, en términos de zona de incumbencia, a la parte costera que iba desde Mar del Plata a Puerto Madryn.

${ }^{2}$ Informe del Servicio de Inteligencia de la Prefectura Naval Argentina, "Memorándum 8687IFI-Nro27 'EESC'/76” del 22 de marzo de 1976.

53 A pocos meses de este señalamiento, en julio de 1976, aparecieron los cuerpos sin vida de los obreros gráficos y gremialistas Enrique Heinrich y Miguel Ángel Loyola arrojados en un descampado en las afueras de la ciudad. Ellos habían sido protagonistas de reclamos salariales y laborales ante la empresa de los Massot, durante los años previos al golpe de Estado. Véase ZAPATA, Ana Belén, Páginas Manchadas. Conflictividad laboral entre los gráficos y La Nueva Provincia en vísperas de la dictadura de 1976, Tesina de Licenciatura en Historia, Universidad Nacional del Sur - Mimeo, Bahía Blanca, 2008. 
«situación legal de cada sindicato»54. La actividad que los servicios entendían como "normal" era solo el servicio vinculado a las obras sociales, se especificaba en detalle la conformación de la última comisión directiva de cada gremio y se consignaban los integrantes de la misma que habían sido ya detenidos por la ARA y cuál había sido su posterior situación de traslado o liberación. De esta forma se detallaban aspectos de los sindicatos de Conductores y Maquinistas, de los Ferro portuarios, los trabajadores del Estado de ATE, empleados nucleados en SUPA, SUPE, UPCN, COPEL, SCEP y de $\mathrm{SPBB}$, todos sectores vinculados a la actividad productiva del Puerto de Ingeniero White. La actividad sindical en gran parte de Bahía Blanca había sido cancelada.

\section{Conclusiones}

Constatamos a lo largo de este trabajo que el accionar represivo ejercido por ARA sobre trabajadores se concretó desde una intencionalidad disciplinadora de los espacios de trabajo, productivos/industriales de su incumbencia o ubicados en sus zonas de acción, los cuales resultaron afectados y reconfigurados durante la dictadura en las dos regiones analizadas aquí.

Para el caso de Ensenada y el ARS la incumbencia institucional de la Armada Argentina en la empresa y el entramado territorial en el cual el astillero se encontraba emplazado - área natural de acuerdo al Plan de Capacidades para el arma - profundizó las condiciones de indefensión de sus trabajadores. La voluntad represiva de la FT5 sobre los trabajadores del astillero tuvo proyección regional, y ese disciplinamiento social, que implicó el terror y la re-composición hegemónica del orden en la empresa, se ancló en percepciones de larga data entre los marinos sobre la pertenencia de la empresa a la fuerza. Es decir, la crudeza represiva sobre los trabajadores del ARS, si bien coincidió con los marcos generales del plan dictatorial, encontró ribetes particulares, de fuertes rasgos revanchistas, y se vio imbuida de intereses propios a las lógicas de un sector de la oficialidad que procuró el extremo disciplinamiento de un colectivo obrero que se desempeñaba en un ámbito considerado propio por los marinos.

Para el caso de Bahía Blanca y su zona portuaria, sostenemos que la preponderancia de la ARA dentro de ciertos espacios laborales y colectivos de obreros respondió a su jurisdicción asignada, pero eso no significó la no actuación en otros espacios productivos locales y más especialmente los relacionados a sectores de poder con los

54 Mem 8687 IF_I No8 “C”/976. Bahía Blanca, 14 de junio de 1976. 
que la ARA había construido ciertas afinidades particulares - un ejemplo de esto fue el vínculo de la ARA con el sector empresarial del diario "La Nueva Provincia”. La ARA resolvió la represión a trabajadores en lo que llamó la «lucha antisubversiva» y lo hizo con absoluta prioridad en la región; sobre todo sin perder de vista esa potencialidad de Bahía Blanca en términos de desarrollo económico y productivo que conformó una representación propia de la época y de los sectores influyentes que la construyeron a merced de sus intereses. Este orden de cosas nos permite arrojar una posible lectura sobre por qué los principales actores que resistieron desde luchas previas cuando ese proyecto los apremiaba en sus condiciones de trabajo, fueron finalmente los sectores afectados ya en dictadura. En contrapartida, la represión buscó aleccionarlos frente a posibles surgimientos de "focos conflictivos" que atentarían contra la concreción del tan ansiado "despegue productivo".

En líneas generales describimos el PLANCINTARA como un marco que estandarizó prácticas de coordinación represiva, aunque algunas de ellas ya estaban en vigencia y habían sido desarrolladas por grupos para-estatales, abocadas a la destrucción de las personas y organizaciones que habían encabezado las luchas sindicales en el bienio anterior en las regiones aquí analizadas. Esta coordinación represiva se vio expresada concretamente tanto en la comunicación de los servicios de inteligencia de las distintas fuerzas, como en la circulación de las víctimas por dependencias militares y CCD dependientes tanto de Ejército como de Armada y de otras fuerzas de seguridad. En este escrito marcamos la distinción de estas regiones, analizadas frente a la lógica concentracionaria y represiva que caracterizó al centro clandestino emblema del terror instaurado en la Escuela de Mecánica de la Armada (ESMA) por la ARA, donde la permanencia de algunas de víctimas secuestradas resultó mucho más extendida en el tiempo, frente a los casos estudiados en los cuales la circulación de las víctimas entre diversas dependencias fue lo que primó. Por su parte, observamos que, la acción represiva de la ARA en estas regiones se impregnó de las lógicas e intereses empresariales - estatales y privados - que indicaron que diferentes colectivos obreros organizados y movilizaron se constituyeron en objetivo central del disciplinamiento mediante el terror de Estado y que, finalmente, la ARA funcionara como fuerza de ocupación en las localidades emplazadas en sus ámbitos naturales y zonas de incumbencia. 


\section{* Los autores}

Ivonne Barragán, doctoranda en historia en la Universidad Nacional de Buenos Aires, becaria del Consejo Nacional de Investigaciones Científicas y Técnicas (CONICET), se interesa por los procesos de disciplinamiento, violencia y represión a colectivos obreros en empresas estatales bajo gestión de la Armada Argentina. En la actualidad indaga en la conformación de repertorios políticos en las fuerzas armadas con vistas a la represión a la clase trabajadora en las décadas de 1960 y 1970.

URL: < http://www.studistorici.com/progett/autori/\#Barragan >

Ana Belén Zapata, Doctora en Historia por la Universidad Nacional de La Plata (UNLP) y docente regular de la Facultad de Filosofía y Letras en la Universidad de Buenos Aires (UBA) de la materia Teoría e Historia de la Historiografía. Es becaria posdoctoral del Consejo Nacional de Investigaciones Científicas y Técnicas (CONICET) Ha publicado distintos artículos sobre la temática de la conflictividad obrera en los años '60 y '70 en Argentina y sobre la represión en la última dictadura militar de 1976 en Argentina.

URL: < http://www.studistorici.com/progett/autori/\#Zapata >

\section{Per citare questo articolo:}

BARRAGÁN, Ivonne, ZAPATA, Ana Belén, «Dictadura militar y represión a la clase trabajadora. La Armada Argentina, marco doctrinario y operaciones represivas en perspectiva regional para los casos de Ensenada y Bahía Blanca», Diacronie. Studi di Storia Contemporanea : Le dittature militari: fisionomia ed eredità politica, 29/12/2015, URL:< http://www.studistorici.com/2015/12/29/barragan-zapata_numero_24/ >

\section{Diacronie Studi di Storia Contemporanea $\beta$ www.diacronie.it}

Risorsa digitale indipendente a carattere storiografico. Uscita trimestrale. redazione.diacronie@hotmail.it

Comitato di redazione: Jacopo Bassi - Luca Bufarale - Elisa Grandi - Antonio César Moreno Cantano - Deborah Paci - Fausto Pietrancosta - Alessandro Salvador - Matteo Tomasoni - Luca Zuccolo

Diritti: gli articoli di Diacronie. Studi di Storia Contemporanea sono pubblicati sotto licenza Creative Commons 3.0. Possono essere riprodotti e modificati a patto di indicare eventuali modifiche dei contenuti, di riconoscere la paternità dell'opera e di condividerla allo stesso modo. La citazione di estratti è comunque sempre autorizzata, nei limiti previsti dalla legge. 